\title{
Non-invasive cell counting of adherent, suspended and encapsullated mammalian cells using optical density
}

\author{
$\overline{\text { Ayesha Aijaz', Dylan Trawinski', Scott McKirgan' \& Biju Parekkadan }{ }^{*, 1}}$
}

\section{ABSTRACT}

In situ measurement to determine mammalian cell number in a non-invasive, non-destructive and reagent-free manner is needed to enable continuous cell manufacturing. An analytical method is presented for non-invasive cell counting by conducting multiwavelength spectral analysis of mammalian cells achieving a minimal detectable cell count of 62,500 at $295 \mathrm{~nm}$. Light absorbance was insensitive to culture volume, giving an absolute cell count rather than a concentration. The activation state of cells was also considered. The study was extended to quantification within polymeric microcapsules as an advanced substrate for mammalian cell growth in bioreactor formats and resulted in an offset directly correlating with the absorbance maxima of the polymer. These studies provide feasibility for optical density as a simple end point to indirectly quantify mammalian cell number for continuous monitoring of cell cultures.

\section{METHOD SUMMARY}

Cell type and anchorage-dependent cells versus suspension cells, as well as cell state (activated vs unactivated), were assessed for changes in optical density to develop an analytical method for cell counting. A multiwavelength spectral analysis was conducted from 200 to $800 \mathrm{~nm}$ with a $5-\mathrm{nm}$ step size to detect peak and minimal detectable cell absorbance. The optical density of cellladen polymeric microcapsules was also evaluated.

\section{KEYWORDS}

biomanufacturing $\cdot$ bioprocess $\cdot$ cell therapy • optical density • optical sensor

'Department of Biomedical Engineering, Rutgers University, New Brunswick, NJ 08854, USA; *Author for correspondence: biju.parekkadan@ rutgers.edu

BioTechniques 68: 35-40 (January 2020) 10.2144/ btn-2019-0052
Rapid, non-invasive and accurate determination of mammalian cell growth is critical for monitoring during many industrial bioprocesses. Several viability tests are used, such as Trypan Blue exclusion, to monitor cell density and viability, and the equipment required to automate this process is commercially available [1-3]. However, these tests are generally destructive assays that can result in contamination and enzymatic cell detachment, as in the case of anchoragedependent cells. They also increase operator time and effort and instrumentto-instrument variability [4] and have low throughput, all of which result in an unmet need for the development of inline modules to monitor cell density. A non-invasive imaging technique that can be applied flexibly to closed-system cell cultures of different formats could enable real-time quantification and process control feedback, an important criterion for realizing the potential for continuous biomanufacturing.

Examining the optical density of a cell culture is a non-invasive, labelfree technique that is widely used to quantify microorganisms during bacterial cell expansion [5]. Microorganisms contain numerous macromolecules that will absorb light, including DNA $(254 \mathrm{~nm})$, proteins $(280 \mathrm{~nm})$, cytochromes (400-500 nm) and possibly cell pigments [6]. Bacterial cultures are typically measured around $600 \mathrm{~nm}$, where light is scattered by the cells and the electrical signal detected by a spectrophotometer is weaker than with a cell-free solution [5]. Optical density methods are increasingly being integrated into highthroughput protein expression platforms using various wavelengths. Commercial devices for inline monitoring of cell growth include those from BugLab (CA, USA) and IPRASENSE (France). The BugLab device uses an infrared light source to measure cell concentration by detecting scattered light from cells across a transparent vessel $[7,8]$. The IPRASENSE device provides an additional advantage of measuring cell density and viability using holographic imaging [9]. A flask density reader developed by the Genomics Institute of the Novartis Research Foundation (CA, USA) has been integrated onto a GNF Systems ${ }^{\mathrm{TM}}$ (Genomics Institute) automated protein expression platform to allow rapid evaluation of cell densities in suspension mammalian cell cultures. The flask density reader utilizes a 660-nm Keyence IB-05 Laser Thrubeam Sensor (Japan) to detect attenuated light from the cells [10]. The need for specialized equipment and a lack of understanding of the specificity and sensitivity of these methods limit adoption of these near-infrared approaches. Moreover, these techniques are also limited by the intricate process required to position the optical components and flasks on the sensor, as the angles between the optical source and the detector can result in different sensitivities and calibrations, thus affecting the reproducibility of these techniques. Additionally, the angle governs sensitivity to higher or lower cell concentrations.

Here, we have conducted a thorough investigation of optical density analysis using wavelengths found on a standard, commercially available spectrophotometer under the hypothesis that the simple use of light absorbance of macromolecules can serve as an indirect measure of cells in culture. Mammalian cell cultures that were either adherent or suspended cells were evaluated in a range of $200-800 \mathrm{~nm}$, with an optimal range detected at $250-350 \mathrm{~nm}$, to determine the feasibility and sensitivity of the technique. This analytical method was also studied in the context of changing sample volume to evaluate its use in scale-up, as well as in encapsulated 
cell culture where a polymeric substrate is used to isolate cells and requires additional accounting. An additional goal of this study was to optimize the optical density counting process by determining the ideal wavelength for adherent cells, suspension cells and polymeric particles such that the vessel itself contributes only minimally to the optical density.

\section{MATERIALS \& METHODS Cell culture}

Human mesenchymal stromal cells (MSCs) were isolated from commercially available bone marrow aspirates (Lonza Group, MD, USA), grown as previously reported [11] and propagated in Alpha MEM (Gibco, MA, USA) supplemented with $10 \%$ fetal bovine serum (FBS; Hyclone, UT, USA). Cells were expanded in T-225 flasks and were used for experiments between passages 3 and 7 . For multiwavelength spectral analysis, cells were trypsinized and counted. Equal numbers of cells were resuspended in $100 \mu \mathrm{l}$ (1x), $200 \mu \mathrm{l}(2 \mathrm{x})$ or $400 \mu \mathrm{l}(4 \mathrm{x})$ volumes and plated in flat-bottom, 96-well plates. Jurkat, Clone E6-1 (ATCC ${ }^{\circledR}$ TIB-152 $^{\text {TM }}$ ) cells purchased from ATCC (VA, USA) were propagated in RPMI-1640 medium (ATCC) supplemented with $10 \%$ FBS (Gibco) in T-75 flasks in an upright position. Cells were used as unactivated or activated cells and transferred to flat-bottom, 96 -well plates in $1 \times, 2 x$ or $4 x$ volumes for spectral analysis when they reached a density of $1 \times 10^{6} / \mathrm{ml}$.

\section{Multiwavelength spectral analysis}

Multiwavelength transmission spectra of mammalian adherent or suspended cells were recorded on a Varioskan ${ }^{T M}$ LUX multimode microplate reader (Thermo Fisher Scientific, MA, USA) at $200-800 \mathrm{~nm}$ with a 5-nm step size. To generate a standard curve and detect the cut-off threshold (minimum cell count that can be reliably detected), $1 \times 10^{6}$ cells were manually counted on a hemocytometer and serially diluted in complete media. Cells were transferred to flat-bottom, 96-well plates and read in incremental volumes of $100 \mu \mathrm{l}(1 \times), 200 \mu \mathrm{l}$ $(2 x)$ or $400 \mu \mathrm{l}(4 \times)$ while keeping the cell number constant. Calibration curves were plotted for MSCs and Jurkat Tcells as examples of anchorage-dependent and suspension cells, respectively, to account for how different cell types attenuate light.
The data were repeated in triplicate, and absorbance spectra were recorded at $200-800 \mathrm{~nm}$ using a Varioskan LUX multimode microplate reader. The measurements were executed from the top with a 12 -nm path length. Absorbance of the vessel itself was subtracted, and a wavelength range was selected that resulted in appreciable absorbance differences as the serially diluted samples were read. Subsequently, the wavelength that resulted in a readable absorbance value with the minimum number of cells was selected. Analysis of variance was conducted on the $1 \times, 2 \times$ and $4 \times$ volume groups.

\section{Activation \& analysis of Jurkat T cells}

TIB-152 Jurkat cell activation was achieved through incubation of cells with $1 \mu \mathrm{g} / \mathrm{ml}$ of PHA-L (Sigma, MO, USA) and $100 \mathrm{ng} / \mathrm{ml} \mathrm{IL-2}$. Cells were incubated for a period of 4 days. Optical density measurements were made every day. Imaging and flow cytometry were conducted on day 4 . Flow cytometry was used to assess the activation state of cells. Collected cells were washed twice in FACS buffer (phosphate-buffered saline containing $2 \% \mathrm{v} / \mathrm{v}$ FBS) and 2-mM EDTA (Sigma) and resuspended in 200 ul of FACS buffer. All flow cytometry was performed using a FACSCanto $^{\text {TM }} \|$ (Becton Dickinson, NJ, USA). Flow cytometry analysis was performed in FlowJo 8.7.3 (Tree Star, OR, USA). Cells were gated to analyze cell granularity on side scatter plots.

\section{Microencapsulation}

Empty or cell-laden microspheres were formed as previously reported [12]. Briefly, hydrogel precursor solution was formed by combining $0.1-\mathrm{g} / \mathrm{ml} 10-\mathrm{kDa}$ poly(ethylene glycol) diacrylate (PEGDA, 10\% w/v) (Laysan Bio, AL, USA) with $1.5 \% \mathrm{v} / \mathrm{v}$ triethanolamine/ HEPES-buffered saline ( $\mathrm{pH} 7.4), 37-\mathrm{mM}$ 1-vinyl-2-pyrrolidinone and 0.1-mM eosin $Y$, with or without MSCs or Jurkat T cells, for a final concentration of $1.5 \times 10^{4} \mathrm{cells} / \mu \mathrm{l}$. A hydrophobic photoinitiator solution containing 2,2-dimethoxy-2-phenyl acetophenone in 1-vinyl-2-pyrrolidinone $(300 \mathrm{mg} /$ $\mathrm{ml}$ ) was combined in Sigma mineral oil $(3 \mu \mathrm{l} /$ $\mathrm{ml}$; embryo-tested, sterile-filtered). The cellprepolymer suspension was added to the mineral oil solution and emulsified by vortexing for $4 \mathrm{~s}$ in ambient light and then for an additional $3 \mathrm{~s}$ under white light. The vortex was then stopped, and the emulsion was exposed to white light for $20 \mathrm{~s}$ with a vortex pulse at $10 \mathrm{~s}$. Crosslinked microspheres were isolated by the addition of $1 \mathrm{ml}$ complete media followed by centrifugation at $300 \times g$ for $5 \mathrm{~min}$. The oil layer was removed by aspiration, and pelleted microspheres were resuspended in media and placed in a 12-well plate with $3 \mathrm{ml}$ culture medium. Microencapsulated cells were maintained in a humidified incubator at $37^{\circ} \mathrm{C}$ and $5 \% \mathrm{CO}_{2}$. Monolayer cells were trypsinized and counted with a hemocytometer, and a serial dilution was used as a standard curve. CellTiter $96^{\circledR}$ AQueous One Solution Reagent (Promega, WI, USA) at $200 \mu \mathrm{l}$ was added into each well, and plates were incubated for $3 \mathrm{~h}$ in a humidified incubator at $37^{\circ} \mathrm{C}$ and $5 \% \mathrm{CO}_{2}$. The amount of soluble formazan produced by cellular reduction of the tetrazolium compound (3-[4,5-dimethylthiazol-2-yl]-5-[3carboxymethoxyphenyl]-2-[4-sulfophenyl]$2 \mathrm{H}$-tetrazolium, inner salt) was measured by reading the absorbance of the medium at $490 \mathrm{~nm}$.

\section{RESULTS \& DISCUSSION}

Inline monitoring of cell growth in fed-batch cultures is becoming increasingly critical in the success of robust manufacturing of biopharmaceuticals and cell-based therapies. Optical density is widely utilized for estimation of biomass concentrations in microbial cultures such as analysis of growth stage, cell dry weight and cell count $[13,14]$. The derivation of cell concentration or number is achieved in accordance with the Beer-Lambert's law [15]. These measurements of optical density are based on the phenomena of light scattering and absorption. In single-phase homogeneous solutions, light attenuation is largely contributed by absorption; however, in mixtures of multiple phases, scattering significantly increases light attenuation due to differences in refractive index [16]. We applied this concept to the measurement of cell densities by analyzing multiwavelength transmission spectra of cells and ultimately polymeric microcapsules and then extending the measurements to cell-laden microcapsules to evaluate the versatility of this technique. We performed a set of calibrations while taking into account relevant parameters such as the difference in refractive index 

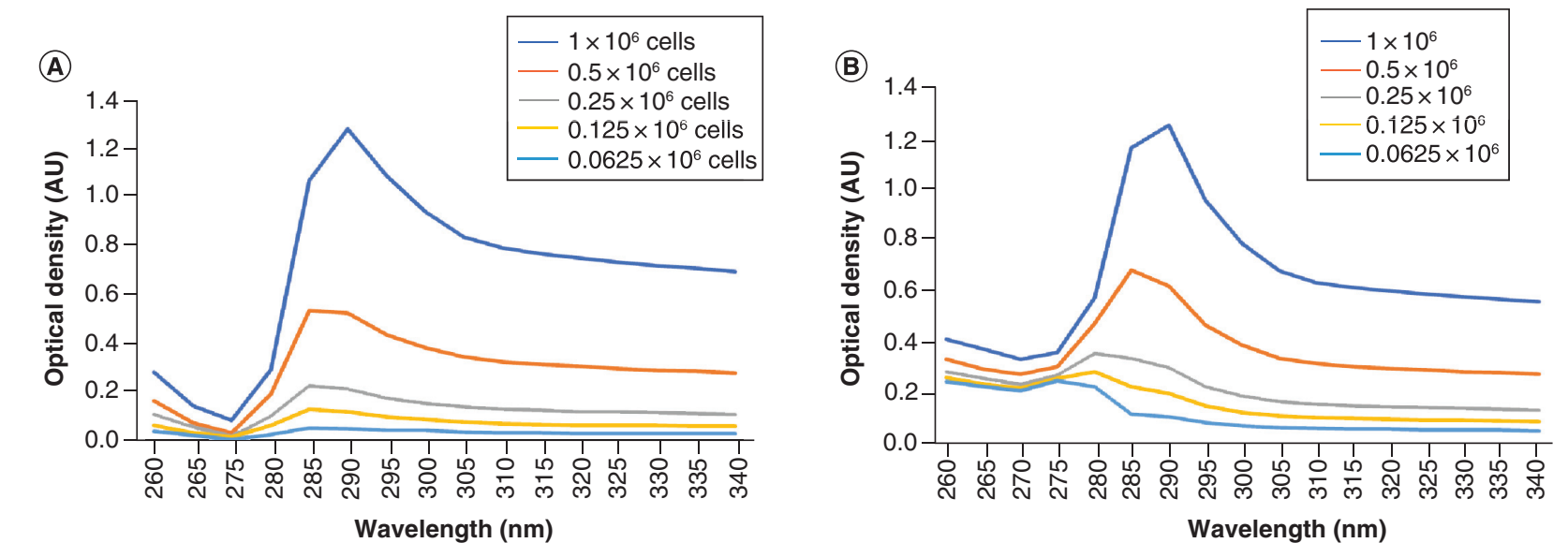

Figure 1. Multiwavelength spectra of (A) anchorage-dependent cells and (B) suspension cells.

of anchorage-dependent and suspension cells, the effect of growth media and attenuation from polymeric microcapsules.

Initial measurements were conducted in a wavelength range of $200-800 \mathrm{~nm}$ with a step size of $5 \mathrm{~nm}$. Wavelengths above $350 \mathrm{~nm}$ were excluded from further analysis as they did not present significant changes in absorbances over serial dilutions for cell numbers. Wavelengths above $350 \mathrm{~nm}$ were further excluded so that the vessel material has minimal contribution to optical density. Multiwavelength transmission spectra for cell densities of 10,000 cells/ $\mu$ l to as low as 625 cells/ $\mu$ l for anchorage-dependent human MSCs and suspension Jurkat T cells demonstrated absorbance maxima at $260 \mathrm{~nm}$ with subsequent increases of $275-290 \mathrm{~nm}$. An absorbance maximum at $290 \mathrm{~nm}$ signified both absorption and scattering information from the sample. Spectra in the region of 300-800 nm do not demonstrate marked changes, and no absorbance peaks were detected in this region (data not shown). Spectra in this region are mainly indicative of scattering. We believe that the absorbance from the vessel itself becomes so high at wavelengths above $300 \mathrm{~nm}$ that it results in an unappreciable difference in absorbance between successively diluted cell samples; thus, samples with low cell numbers are difficult to quantify at these wavelengths.

Following a range-finding experiment, the minimal detectable cell count was $6.25 \times 10^{4}$ cells captured in the range of $280-340 \mathrm{~nm}$, with the highest absorbances at $295 \mathrm{~nm}$ for both anchorage-dependent and suspension cells. Quantifying cell number changes of $>2.5 \times 10^{5}$ cells showed promise due to an improved signal-to-noise ratio (Figure $1 \mathrm{~A} \& \mathrm{~B})$.

Indirectly measuring light absorption was found to be feasible as a proof-of-concept, although further research is necessary to test the precision of this method to minimize false positives; for example, one potential limitation of indirect cell counting using light absorbance is that cell aggregates can be miscounted as single cells. We attempted to confirm the changes in light absorbance in the presence of aggregates and changes in cell morphology using activated Jurkat T cells. The Jurkat T cells were activated with $\mathrm{PHA}$, a mitogen that causes the differentiation of $\mathrm{T}$ cells into effector cells [17]. PHA activation led to a morphology change by microscopy between unactivated T cells (Figure 2A) and activated T cells (Figure 2B). Side scatter analysis demonstrated changes in PHA activated cells compared with unactivated controls (Figure 2C \& E) due to increased granularity of the differentiated cells (Figure 2D \& F). We also analyzed whether or not the activated state over time had any effect on the optical density of the cells. Absorbance measurements were made over the 4-day period after activation and was found to be unchanged among groups (Figure $2 \mathrm{G}$ ).

Because light absorption is related to concentration, we also analyzed the effect of volume on the observed optical density by varying the sample volume while keeping the cell number constant. The multiwavelength spectral analysis was repeated with equal cell numbers in
$1 \times, 2 \times$ or $4 \times$ volumes in an attempt to find a wavelength resulting in absorbances unaffected by volume changes. Analysis of variance followed by Tukey's post hoc test yielded significantly higher optical density at $1 \times$ sample volume compared with $2 \times$ and $4 \times$ at $285 \mathrm{~nm}$ and $290 \mathrm{~nm}$ for MSCs (Figure $3 \mathrm{~A}$ ). No statistical significance was observed among the $1 \times, 2 \times$ and $4 \times$ groups $(p>0.05)$ at $295 \mathrm{~nm}$. Jurkat T cells demonstrated a similar trend (Figure 3B), such that sample volume did not have an effect on the observed optical density at $290 \mathrm{~nm}$ and $295 \mathrm{~nm}(\mathrm{p}>0.05)$, and the $1 \times$ sample volume at $285 \mathrm{~nm}$ was significantly higher compared with the corresponding $2 x$ and $4 \times$ samples. These data suggest that $295 \mathrm{~nm}$ can be an appropriate wavelength to get an absolute cell count as it is insensitive to volume changes.

Spectral analysis was extended to PEGDA microcapsules. Microcapsule counts from $500-\mu$ l samples were $1.3 \times 10^{5} \pm 0.3 \times 10^{5}$ capsules and were used to plot the calibration curves. A multiwavelength spectral analysis of the polymeric microcapsules was conducted to find the absorbance maxima. PEGDA microcapsules demonstrate peak optical densities between 220 and $260 \mathrm{~nm}$, with an absorbance maximum at $240 \mathrm{~nm}$, independent of particle concentration. Measured optical density demonstrated a direct relationship with particle concentration when analyzed between 280 and $340 \mathrm{~nm}$ (Figure 4).

Comparison of multi-transmission spectra of microcapsules, monolayer or encapsulated MSCs and suspension or encapsulated Jurkat $\mathrm{T}$ cells demon- 

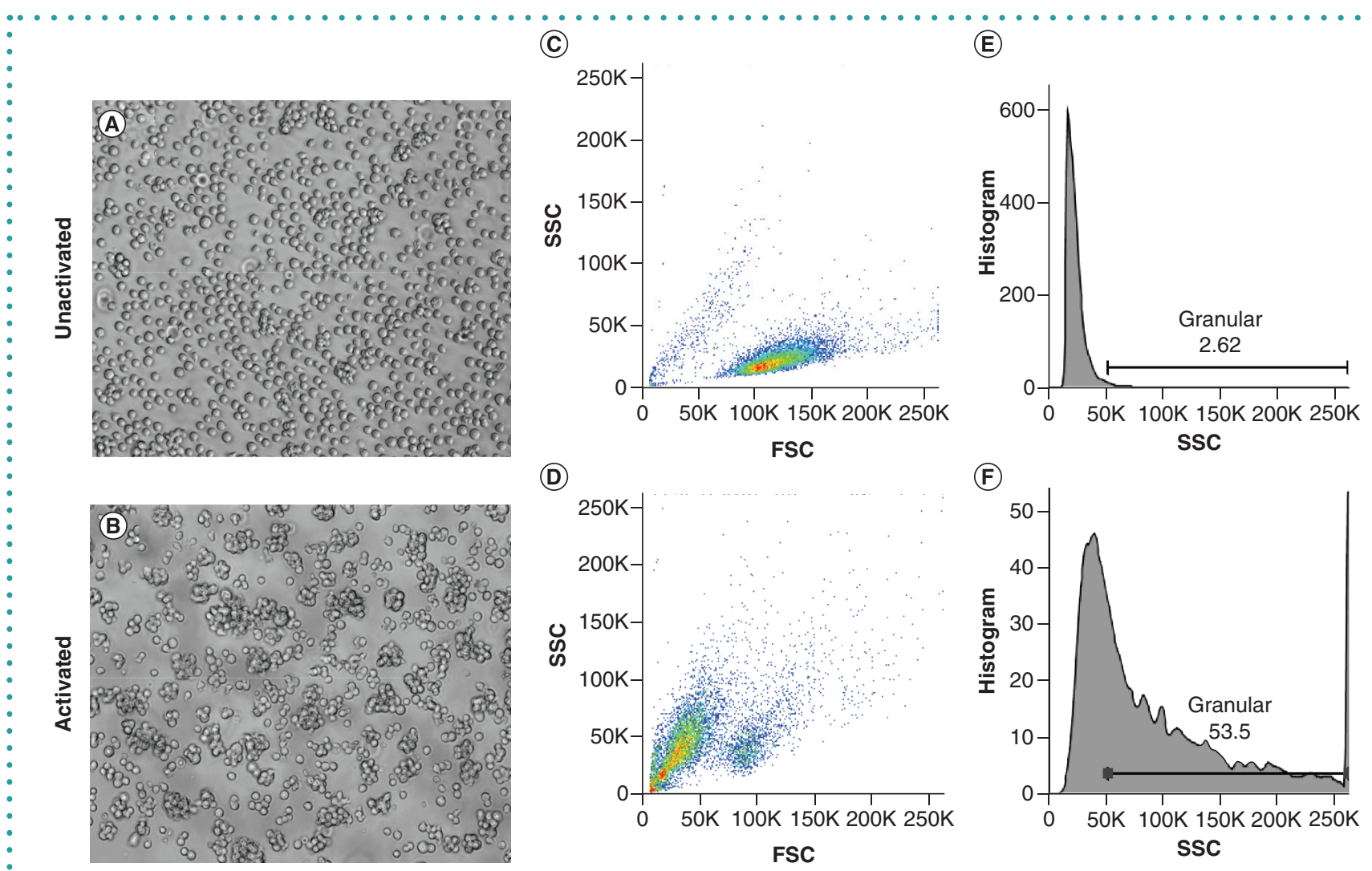

(G)

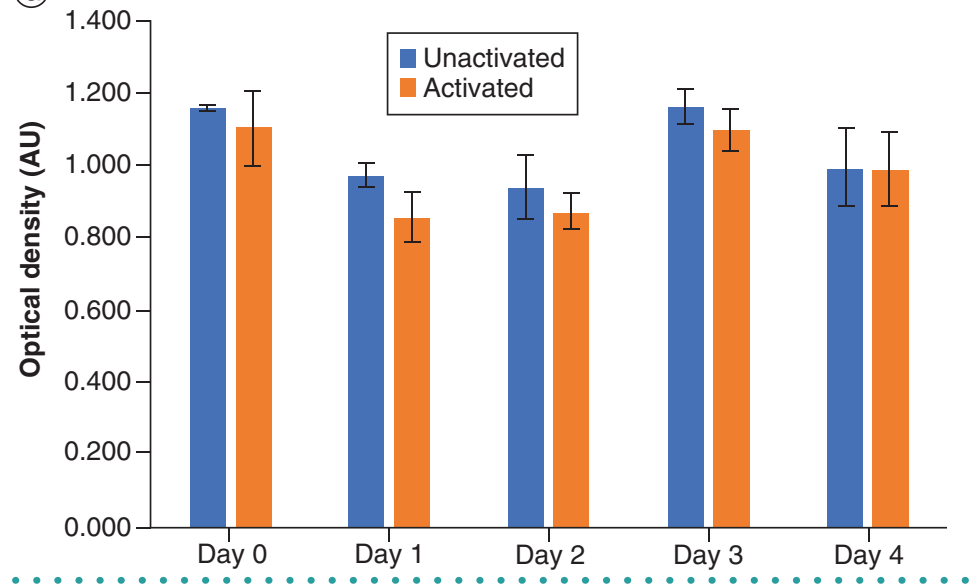

Figure 2. Effect of cell state (activated vs unactivated) on cell absorbance. Photomicrograph of (A) unactivated and (B) activated Jurkat T cells. (C-F) Flow cytometry analysis of cell state. (G) Absorbance of unactivated and activated Jurkat cells at $295 \mathrm{~nm}$.

FSC: Forward scatter; SSC: Side scatter.

strated a leftward offset due to attenuation from PEGDA. We observed that polymeric capsules demonstrate peak absorption at $240 \mathrm{~nm}$ and cells have absorbance maxima around $290 \mathrm{~nm}$. In order to estimate encapsulated cell densities within microcapsules, a 295-nm wavelength was selected. This wavelength provided the greatest difference between absorbance of cells and microcapsules. The shift in absorbance maxima to a lower wavelength with cell-laden capsules may be potentially due to the contribution from the PEGDA matrix offsetting the maxima to $280 \mathrm{~nm}$.

The mechanism of optical sensing of cells may give clues to further improve the precision of this technique. The analytical method presented allows detection of at least $6.25 \times 10^{4}$ cells with absorbance maxima at $295 \mathrm{~nm}$ and was unaffected by the morphological features of cells and sample volumes. The absorbance peak of cells around $290 \mathrm{~nm}$ is potentially due to the protein content of the cells, specifi- cally dominated by aromatic amino acids and peptide bonds in the peptide chains. Aromatic rings of amino acids demonstrate absorption in the range of $230-300 \mathrm{~nm}$, and the smaller peak at $260 \mathrm{~nm}$ is possibly results from a contribution by disulfide bonds and intuitively from the nucleic acid content $[18,19]$. It has previously been reported that tyrosine in native proteins shows two absorbance maxima at 280 and $289.5 \mathrm{~nm}$, but tryptophan exhibits absorbance maxima centered at 287 and 
(A)

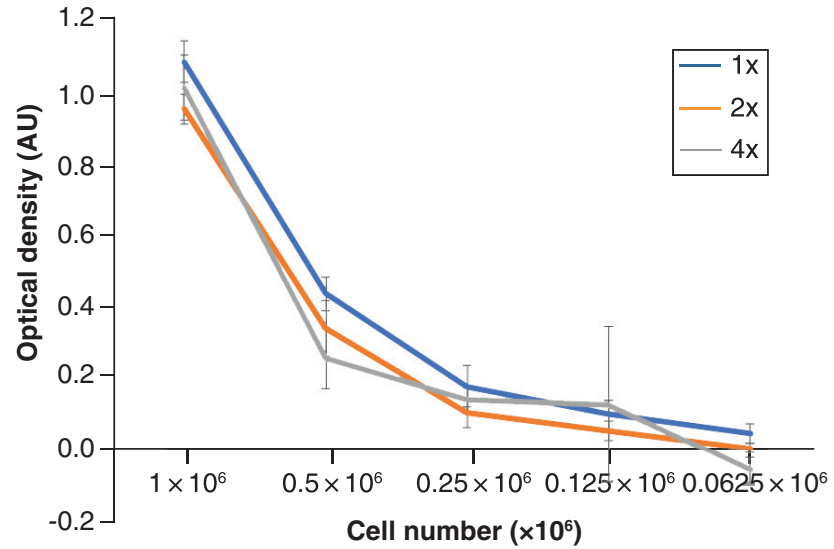

(B)

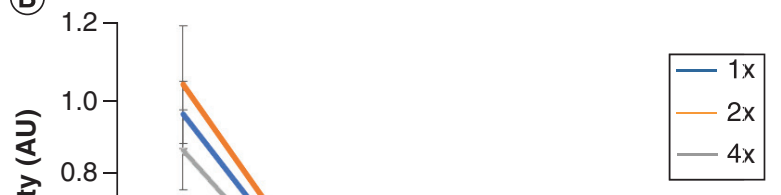

Figure 3. Effect of sample volume on absorbance. Varying the sample volume (constant cell number) did not result in a detectable difference in absorbance. Shown are the optical densities at $295 \mathrm{~nm}$ for (A) MSCs at $1 \times, 2 \times$ and $4 \times$ volume and (B) Jurkat T cells at $1 \times, 2 \times$ and $4 \times$ volume. MSC: Mesenchymal stromal cell.

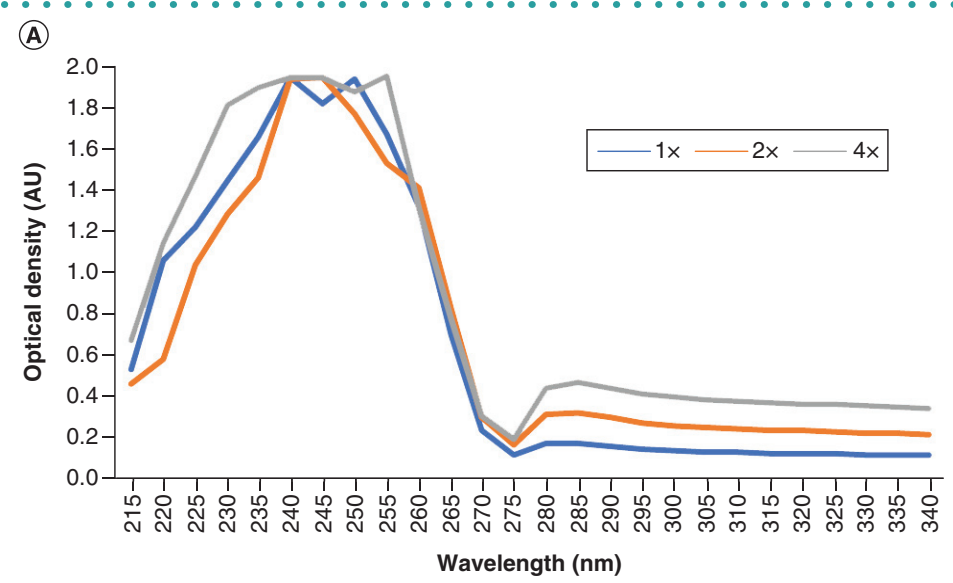

(B)

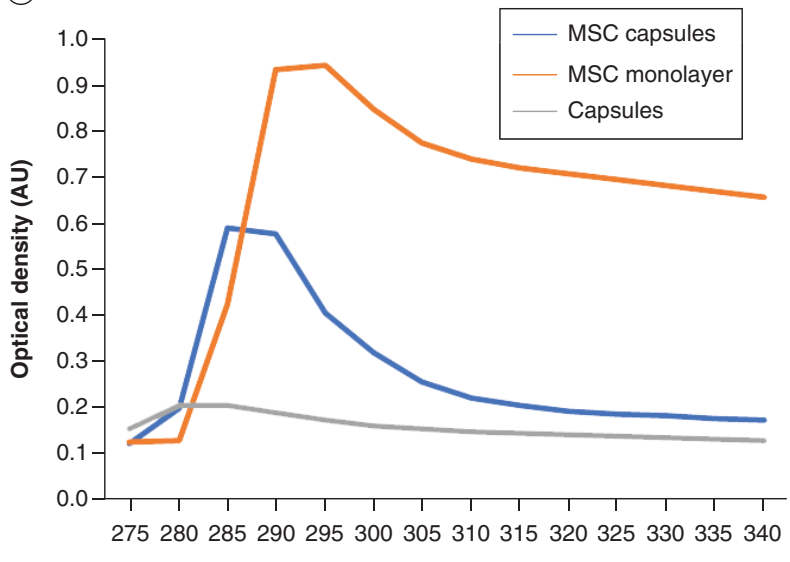

Wavelength $(\mathrm{nm})$
(C)

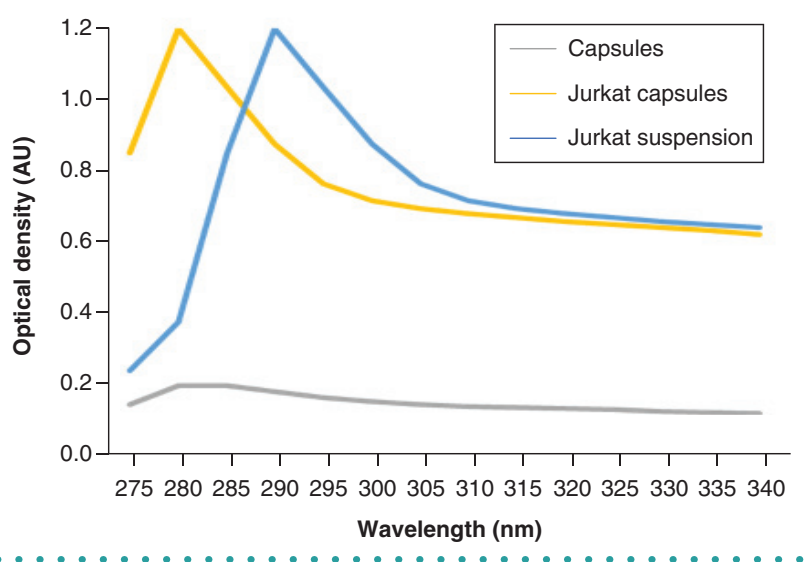

Figure 4. Absorbance of polymeric PEGDA capsules. (A) Multiwavelength spectra of PEGDA capsules at $1 \times, 2 \times$ and $4 \times$ volume. (B) Optical density comparison of polymeric microcapsules, monolayer and encapsulated MSCs. (C) Optical density comparison of polymeric microcapsules, monolayer and encapsulated Jurkat T cells.

MSC: Mesenchymal stromal cell; PEGDA: Poly(ethylene glycol) diacrylate. 
$295 \mathrm{~nm}$ [20-22]. Factors such as $\mathrm{pH}$, ionic strength and sample concentration can alter the absorbance spectrum due to an effect in the secondary, tertiary and quaternary structure [23]. In our methods, the $\mathrm{pH}$ was maintained at $7.2-7.4$, and sample concentration did not influence absorbance. All of our samples from anchorage-dependent and suspension cells demonstrate a characteristic shoulder peak at $290 \mathrm{~nm}$ [24]. We hypothesize that the absorbance spectrum is a sum of protein and nucleic acid components of the cells. Absorption values from the cells and media followed an approximately 2:1 ratio for both MSCs and Jurkat T cells. Mediaonly controls were run at the same time as cellular samples and subtracted out. Absorbance from the media is potentially due to the presence of $0.01-\mathrm{g} / \mathrm{l}$ tryptophan and $0.05-\mathrm{g} / \mathrm{l}$ tyrosine disodium dihydrate. These aromatic amino acids have absorbance maxima between 275 and $280 \mathrm{~nm}$ with a spectral shift of $10-20 \mathrm{~nm}$ if they are buried in hydrophobic domains of folded proteins.

Developing additional strategies to resolve absorbance coming from media versus cells, perhaps using composite measurements of regional imaging of cell-free zones in culture coupled to optical measurements, should be considered to truly enable performing this technique in an automated manner. Turbidity and bubbles that occur in the stirred and aerated culture are another example of issues that can interfere with the sensitive optical measurements. Our results support future evaluation of this method to accurately identify relative, bulk changes in cell numbers, as opposed to precision cell counting, in order to guide process controllers. Finally, creating portable and customized optical sensors that can mold to different cell culture formats may also be critical for large-scale cell expansion systems that have different geometries.

Optical sensing of mammalian cell numbers is a viable method for non-invasive cell counting. This work supports further development of optical methods for non-invasive counting to improve the precision and versatility of this technique for larger scale formats as a step toward utilizing continuous mammalian cell culture systems with automated process controls.

\section{FUTURE PERSPECTIVE}

Due to the constant need for cells serving as workhorses in the biotechnology industry for the production of biologics such as whole proteins and antibodies and the current trend of cell therapies in regenerative medicine, closed-system automated cell counting is becoming increasingly critical. New methods or modifications to existing methods are crucial for optical sensing of cells in culture and will lay the groundwork for future biomanufacturing initiatives to continuously measure cell properties in automated cell growth bioreactor systems.

\section{AUTHOR CONTRIBUTIONS}

A Aijaz and B Parekkadan designed the experiments. A Aijaz and D Trawinski conducted the experiments, analyzed the results and wrote the protocol document. S McKirgan conducted capsule counts, A Aijaz wrote the manuscript, and B Parekkadan edited, revised and finalized the manuscript and figures.

\section{FINANCIAL \& COMPETING INTERESTS DISCLOSURE}

This research was conducted with support under grant nos. R01GM127353 (B Parekkadan) and R01EB012521 (B Parekkadan) awarded by the National Institutes of Health and the Rutgers University TechAdvance fund. The authors have no other relevant affiliations orfinancial involvement with any organization or entity with a financial interest in or financial conflict with the subject matter or materials discussed in the manuscript apart from those disclosed.

No writing assistance was utilized in the production of this manuscript.

\section{OPEN ACCESS}

This work is licensed under the AttributionNonCommercial-NoDerivatives 4.0 Unported License. To view a copy of this license, visit http://creativecommons.org/licenses/ by-nc-nd/4.0/

\section{REFERENCES}

1. Louis KS, Siegel AC. Cell viability analysis using Trypan Blue: manual and automated methods. In: Mammalian Cell Viability: Methods and Protocols. Stoddart MJ (Ed.). Humana Press, NJ, USA, 7-12 (2011)

2. Cadena-Herrera D, Esparza-De Lara JE, RamírezIbañez ND et al. Validation of three viable-cell counting methods: manual, semi-automated, and automated. Biotechnol. Rep. (Amst.) 7, 9-16 (2015).

3. Huang L-C, Lin W, Yagami M et al. Validation of cell density and viability assays using Cedex automated cel counter. Biologicals 38(3), 393-400 (2010).
4. Lew C, Gomez JA, Rhyner MN. Instrument-to-instruAnalyzer Beckman Coulter, CA, USA (2012). https:// mediz. media.beckman.com/-/media/pdf-assets/application-notes/flow-vi-cell-application-note-instr
ment-variability-in-automated-viability.pdf

5. McBirney SE, Trinh K, Wong-Beringer A et al. Wavelength-normalized spectroscopic analysis of Staphylococcus aureus and Pseudomonas aeruginosa growth rates. Biomed. Opt. Express. 7(10), 4034-4042 (2016).

6. Sukumaran S. Concentration determination of nucleic acids and proteins using the micro-volum BioSpec-nano-spectrophotometer. J. Vis. Exp. 48, 2699 (2011).

7. Rue SM, Anderson PW, Miller JM et al. Mammalian cell culture density determination using a laser throughbeam sensor. BioTechniques. 65(4), 224-226 (2018).

8. Ude C, Schmidt-Hager J, Findeis M et al. Application of an online-biomass sensor in an optical multisensory platform prototype for growth monitoring of biotechniplatform prototype for grow honitoring of biotechnical relevant microorganism and cell lines in single-use (2014).

9. Allier C, Bordy T, Hervé L et al. Label-free cell viability assay using lens-free microscopy. SPIE BIOS 10497, 104970B (2018).

10. Rue SM, Anderson PW, Miller JM et al. Mammalian cell culture density determination using a laser throughbeam sensor. BioTechniques 65(4), 224-226 (2018).

11. Parekkadan B, van Poll D, Megeed Z et al. Immunomodulation of activated hepatic stellate cells by mesenchymal stem cells. Biochem. Biophys. Res. Commun. 363(2), 247-252 (2007).

12. Aijaz A, Faulknor R, Berthiaume F, Olabisi RMJ. Hydrogel microencapsulated insulin-secreting cells increase keratinocyte migration, epidermal thickness, collagen fiber density, and wound closure in a diabetic mouse model of wound healing. Tissue Eng. Part A. 21(21-22), 2723-2732 (2015).

13. Li E, Mira de Orduña R. A rapid method for the determination of microbial biomass by dry weight using a moisture analyser with an infrared heating source and an analytical balance. Lett. Appl. Microbiol. 50(3), 283-288 (2010)

14. Mauerhofer LM, Pappenreiter P, Paulik C et al. Methods for quantification of growth and productivity in anaerobic microbiology and biotechnology. Folia Microbiol. (Praha.) 64(3), 321-360 (2018).

15. Stevenson K, McVey AF, Clark IBN et al. General calibration of microbial growth in microplate readers. Sci. Rep. 6, 38828 (2016).

16. Swanson NL, Billard BD, Gennaro TL. Limits of optical transmission measurements with application to particle sizing techniques. J. Applied Optics. 38(27), 5887-5893 (1999).

17. Fernández-Riejos P, Goberna R, Sánchez-Margalet V. Leptin promotes cell survival and activates Jurkat T lymphocytes by stimulation of mitogen-activated protein kinase. Clin. Exp. Immunol. 151(3), 505-518 (2008).

18. Fornander LH, Feng B, Beke-Somfai T, Nordén B. UV transition moments of tyrosine. J. Phys. Chem. $B$. 118(31), 9247-9257 (2014).

19. Aitken A, Learmonth MP. Protein determination by UV absorption. In: The Protein Protocols Handbook. Walker JM (Ed.). Humana Press, NY, USA, 3-6 (2009).

20. Antosiewicz JM, Shugar D. UV-Vis spectroscopy of tyrosine side-groups in studies of protein structure. Part 2: selected applications. Biophys. Rev. 8(2), 163-177 (2016)

21. Ragone R, Colonna G, Balestrieri C, Servillo L, Irace GJB. Determination of tyrosine exposure in proteins by second-derivative spectroscopy. Biochemistry. 23(8), 1871-1875 (1984).

22. Servillo L, Colonna G, Balestrieri C, Ragone R, Irace GJAb. Simultaneous determination of tyrosine and tryptophan residues in proteins by second-derivative spectroscopy. Anal. Biochem. 126(2), 251-257 (1982).

23. Fohely F, Suardi N. Study the characterization of spectral absorbance on irradiated milk protein. J. Phys. Conf. Ser. 995, 012056 (2018).

24. Porterfield JZ, Zlotnick A. A simple and general method for determining the protein and nucleic acid conten of viruses by UV absorbance. Virology 407(2), 281288 (2010).

25. Louis KS, Siegel AC. Cell viability analysis using Trypan Blue: manual andautomated methods. In: Stoddart MJ (Ed.). Mammalian Cell Viability: Methods and Protocols. Humana Press, NJ, USA, 7-12 (2011). 